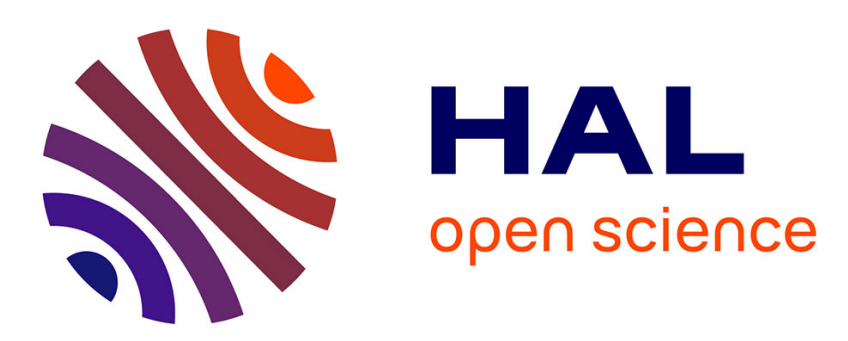

\title{
Prospective study on ocular findings in acute Puumala hantavirus infection in hospitalized patients
}

Nina Hautala, Heikki Kauma, Olli Vapalahti, Saara-Mari Mähönen, Olli Vainio, Antti Vaheri, Timo Hautala

\section{- To cite this version:}

Nina Hautala, Heikki Kauma, Olli Vapalahti, Saara-Mari Mähönen, Olli Vainio, et al.. Prospective study on ocular findings in acute Puumala hantavirus infection in hospitalized patients. British Journal of Ophthalmology, 2010, 95 (4), pp.559. 10.1136/bjo.2010.185413 . hal-00577969

\section{HAL Id: hal-00577969 \\ https://hal.science/hal-00577969}

Submitted on 18 Mar 2011

HAL is a multi-disciplinary open access archive for the deposit and dissemination of scientific research documents, whether they are published or not. The documents may come from teaching and research institutions in France or abroad, or from public or private research centers.
L'archive ouverte pluridisciplinaire HAL, est destinée au dépôt et à la diffusion de documents scientifiques de niveau recherche, publiés ou non, émanant des établissements d'enseignement et de recherche français ou étrangers, des laboratoires publics ou privés. 


\title{
Prospective study on ocular findings in acute Puumala hantavirus infection in hospitalized patients
}

\author{
Nina Hautala ${ }^{1}$, Heikki Kauma ${ }^{2}$, Olli Vapalahti ${ }^{3}$, Saara-Mari Mähönen ${ }^{4}$, Olli Vainio ${ }^{4}$, Antti \\ Vaheri $^{3}$, and Timo Hautala ${ }^{2,4}$ \\ ${ }^{1}$ Department of Ophthalmology and ${ }^{2}$ Department of Internal Medicine, Oulu University Hospital, \\ Oulu, Finland. ${ }^{3}$ Department of Virology, Haartman Institute, University of Helsinki, Finland. \\ ${ }^{4}$ Institute of Diagnostics, Department of Medical Microbiology, University of Oulu, Oulu, Finland.
}

KEYWORDS: hantavirus, intraocular pressure, myopic shift, nephropathia epidemica

Address for correspondence:

Nina Hautala, M.D., Ph.D.

Department of Ophthalmology

Oulu University Hospital

P.O. Box 22, FIN-90029 OYS, Finland

Phone: +358-8-315 3726

E-mail: Nina.Hautala@ppshp.fi 


\section{ABSTRACT}

Aims: To appraise the ocular manifestations of Puumala hantavirus evoked haemorrhagic fever with renal syndrome (HFRS) nephropathia epidemica (NE) and to clarify the mechanisms of ocular changes in the largest series of patients examined to date.

Methods: 92 eyes of 46 patients with serologically proven NE were examined during the acute phase and after clinical recovery. Ocular symptoms were recorded and visual acuity, refraction, intraocular pressure and ocular dimensions were evaluated.

Results: $88 \%$ of the patients experienced decreased intraocular pressure (IOP) $(\mathrm{p}<0.001), 87 \%$ blurred-reduced visual acuity, $87 \%$ conjunctival chemosis, $82 \%$ thickening of the lens $(\mathrm{p}<0.05)$, $78 \%$ myopic shift $(\mathrm{p}<0.001), 64 \%$ shallowing of the anterior chamber $(\mathrm{p}<0.05)$ and $52 \%$ shallowing of vitreous length $(\mathrm{p}<0.05)$ during the acute phase compared to that measured after clinical recovery. In all, $70 \%$ of the patients reported ocular symptoms.

Conclusion: Ocular symptoms and disturbances are common in acute NE and the symmetry of the ocular changes reflects the systemic nature of the disease. A decrease in IOP and myopic shift mainly due to thickening of the lens are evident in the acute disease. The myopic shift only partially explains the visual disturbances supporting the possible multifactorial origin of the ocular findings in patients with NE. 


\section{INTRODUCTION}

Haemorrhagic fever with renal syndrome (HFRS) caused by hantaviruses is common in Europe and Asia [1, 2]. Puumala hantavirus (PUUV) causes HFRS also called nephropathia epidemica (NE) which is widely found, especially in Northern Europe [1]. In Finland, for example, 5\% of the population have antibodies against PUUV [3]. Recently, an increasing number of NE cases has been detected in Central and Western Europe, possibly due to climate change [4]. The virus is spread by bank voles and there is a cyclic variation in incidence of NE with peaks in every third to fourth year. Human infection is thought to occur by inhalation of the aerosolized excreta of infected rodents. After an incubation period of 2-4 weeks, the typical symptoms of NE start with an acute onset of fever, headache, abdominal pain, nausea, diarrhea, impaired renal function, reduced blurred vision, and occasionally haemorrhagic complications. Although most patients recover from NE spontaneously, a few deaths have been reported [5,6] and involvement of the central nervous system (CNS) during acute NE has been demonstrated [6-8].

The ocular symptoms associated with acute fever, renal failure, and thrombocytopenia should lead to a suspicion of NE, at least in endemic regions. Despite the highly characteristic nature of the reduced blurred vision in NE, our understanding of the ocular symptoms remains incomplete. Reduced Blurred vision (6-40\%), transient myopia (8-53\%) or myopic shift (19-41\%), change in ocular dimensions, acute glaucoma attacks (0-23\%), decrease in intraocular pressure (0-66\%), anterior uveitis (0-24\%), lid edema (0-77\%), conjunctival chemosis (3-57\%), retinal edema (0$15 \%)$, conjunctival and retinal haemorrhages (0-7\%), diplopia (0-15\%), pupillary defect (single case), and anisocoria (0-7 \%) have been reported in patients with NE [9-21]. However, it is difficult to understand the mechanisms of these ocular symptoms since often the findings are based on case 
reports [9-15] or studies involving groups of patients in very different clinical stages of the disease or different degrees of severity [16-20]. For example, controversy exists in understanding of the possible changes in intraocular pressure $[11-13,15,16,19]$ as well as in occurrence of anterior uveitis during the acute phase of the disease $[10,11,13,15,16,20]$. Brief reports on ocular symptoms and findings similar to those seen in NE have been described in HFRS caused by other hantaviruses $[1,2]$.

We evaluated 46 acute-phase NE patients and re-examined them one month later; our goal was to clarify the spectrum of ocular manifestations and to elucidate the mechanisms of these features in this largest series of NE patients to date. One major advantage of this prospective study is that the patients had similar degrees of severity in their NE and the examinations for ocular involvement were completed within strict time limits since the onset of symptoms.

\section{MATERIALS AND METHODS}

\section{Patients}

The study patients were recruited from those individuals who were hospitalized for acute NE at the Oulu University Hospital in Northern Finland between September 2005 to February 2008. The patient population and the severity of their clinical symptoms has been described elsewhere [22]. During the study period, 154 patients with moderate to severe illness and a positive acute-phase PUUV antibody finding had been hospitalized according to the discharge register. Of those patients, a clinician contacted the newly diagnosed patients though some eligable patients may not have been contacted because of absence of the study doctors, short hospitalization, or other technical reasons. A comprehensive ophthalmic evaluation was conducted in 50 patients (35 men, 15 females) aged 48 
years on average (range 26-77 years) in the acute phase being repeated in 46 patients one month later.

\section{Study Protocol and Methods}

The study protocol was explained to each patient and they had the right to refuse or withdraw from the study according to the Helsinki Declaration. The study was approved by the Ethics Committee of the Oulu University Hospital and all participants signed an informed consent form.

The ophthalmic evaluation consisted of the determination of refraction and best corrected visual acuity (BCVA), intraocular pressure (IOP) measurements, slit-lamp examination, dilated funduscopy and evaluation of ocular dimensions by ophthalmic echography (Quantel Medical Compact II). The parameters examined were anterior chamber depth (ACD), thickness of the lens, axial length (AXL) of the eye, and length of vitreous cavity (VL). The ultrasound equipment was calibrated and the reliability of the measurements was confirmed by measuring the same parameters (ACD, AXL) also by IOL Master (Zeiss IOL Master Software Version 3.xx). The patients were examined by an ophthalmologist during the acute phase 5-7 (mean 5.9) days after onset of fever and re-examined after 26-52 (mean 36.8) days after the time of clinical recovery.

\section{Statistical methods and data analysis}

The results of the ophthalmic examinations were analysed by SPSS (version 13.0, SPSS Inc., Chicago, Ill., USA) using non-parametric tests: the Wilcoxon signed ranks test was used for normally distributed variables and the Mann-Whitney $U$ test for those variables that were not normally distributed. P-value $<0.05$ was considered statistically significant. 


\section{RESULTS}

\section{Symptoms, findings and visual acuity}

First, the symptoms were recorded (Table 1). In all, $70 \%$ of the patients had complained of a noticeable ocular symptom or frequently, several simultaneous symptoms, during the acute phase. Common symptoms were light sensitivity light sensitiveness, foreign-body sensation and discomfort, and orbital pain. Furthermore, $87 \%$ of the patients reported symptoms suggestive of CNS involvement (headache, nausea/vomiting, or dizziness). In the ophthalmic evaluation, prominent conjunctival chemosis was noted in 80 eyes. Only 1 patient suffered bilateral subconjunctival bleeding. No cases of anterior or posterior uveitis, retinal edema or retinal haemorrhages were recorded.

VA was blurred reduced in 80 eyes of 40 patients $(87 \%)$ during acute NE (Table 1). The mean BCVA was diminished (20/25, range 20/500-20/10) compared to the control assessment (20/16, range 20/30-20/10 ( $<<0.001))$. VA remained unchanged in 9 eyes $(10 \%)$ and was better in 3 eyes $(3 \%)$ in the acute phase compared to the control examination.

\section{Refraction}

A strong tendency was noted towards myopia in the acute phase compared to control examination (Table 2). If all patients were considered as a single group, the mean change in refraction power was $0.5 \mathrm{D}$ towards myopic direction in $\mathrm{RE}$ (range from $-4.5 \mathrm{D}$ to $+0.75 \mathrm{D}, \mathrm{p}<0.001$ ) and $0.5 \mathrm{D}$ in LE (range from $-4.5 \mathrm{D}$ to $+0.75 \mathrm{D}, \mathrm{p}<0.001$ ). Myopic refraction change (mean $-0.7 \mathrm{D}$, range 0.254.5 D, p <0.001) was noted in a total of 68 eyes of 34 patients $(74 \%)$. Refraction remained unchanged in 17 eyes $(18 \%)$ and in 7 eyes $(8 \%)$ refraction changed in the hyperopic direction (mean $+0.4 \mathrm{D}$, range $0.25-0.75 \mathrm{D})$. The changes in refraction power were analogous between $\mathrm{RE}$ and LE in 
an individual patient.

\section{Intraocular pressure}

In all patients, the IOP tended to be significantly lower in the acute phase compared to control phase (Table 2). The differences in IOP between RE and LE were parallel in each individual patient. The IOP had declined (mean $4.5 \mathrm{mmHg}$, range $1-11 \mathrm{mmHg}$ ) in 80 eyes of 40 patients $(87 \%)$ in the acute phase compared to that measured after clinical recovery $(\mathrm{p}<0.001)$. In 9 eyes $(10 \%)$ the IOP remained unchanged during the acute infection and in 3 eyes (3\%) a slight increase in IOP (mean 3 $\mathrm{mmHg}$, range 1-5 $\mathrm{mmHg}$ ) was noted during the acute phase. However, neither of these two patients had IOP over $22 \mathrm{mmHg}$ nor suffered any symptoms of acute angle-closure attack in the acute phase. IOP was measured at the same time of day in each patient to avoid the diurnal variation.

\section{Anterior chamber depth}

Compared to the control phase, mean ACD was shallower in 59 eyes (64\%), deeper in 25 eyes (27\%) and unchanged in 8 eyes $(9 \%)$ in the acute phase. The individual difference in ACD was parallel between RE and LE (Table 2).

\section{Lens}

Compared to the control examination, in the acute phase deepening of the crystalline lens was noted in 75 eyes (82\%), the lens was thinner in 14 of 92 eyes (15\%) and no change was noted in 3 eyes. In the acute phase, the average thickness of the lens was significantly increased (Table 2).

\section{Vitreous length and axial length}

The length of the vitreous cavity was shallower in the acute phase compared to control phase (Table 2). There was no statistical difference in AL between the phases. 


\section{DISCUSSION}

Previous reports have examined the ophthalmic aspects of NE mainly in patients with mild or moderate systemic disease [16, 18-20]. However, controversy exists on some findings, such as changes in IOP, possibly due to variation in time-points at which the ocular findings were recorded during the course of the illness in the earlier studies. In our study, which is the largest series to date concerning ocular involvement in NE, the patients were examined on an average of six days after the onset of symptoms i.e. during the acute febrile and oliguric phase of the illness. They were reexamined soon after their recovery which should rule out the possibility of other potential developing ocular conditions complicating the findings. There are extensive variations in the severity of systemic NE, and this may also influence the ocular manifestations; all our patients experienced moderate or severe disease, which may in part explain the homogenous and consistent results. Interestingly, all our patients displayed ophthalmic findings and $70 \%$ of them suffered marked ocular symptoms. It is obvious that ocular involvement is indeed a common feature of acute NE and in actual fact the findings may be more common than formerly believed [1].

Blurred Reduced vision, which is highly characteristic of NE, is commonly thought to be caused by a myopic shift or transient myopia $[16,18]$, although the precise mechanism of visual disturbance has remained unknown. Previous studies have reported the incidence of transient myopia or myopic shift of $8-53 \%$ in hospitalized patients $[11,13,15,16,18]$. Compared to previous studies, the greater incidence of myopic refraction change in the current study-was $74 \%$, which may be explained by the severity of the systemic disease in our patients. In addition, our patients were examined during the febrile phase of the illness and the majority of the patients were suffering 
ocular symptoms at that time point. The symptoms and ocular findings of NE are known to be transient and examination of refraction at much earlier or later time points could well lead to the different results. Interestingly, the change of refraction towards a myopic direction does not necessarily lead to decreased visual acuity in patients with acute phase of NE. Indeed, the myopic shift may even improve the visual acuity of hyperopic patients when not wearing eyeglasses.

An earlier study from Finland has suggested that myopia is caused mainly by shallowing of the anterior chamber [18]. In our patients, the shallower anterior chamber was shallower in $64 \%$ of the patients in the acute NE and this may partly explain the myopic change in some but not all patients displayed a myopic refraction change. Interestingly, the anterior chamber was deeper in $27 \%$ of the patients in the acute phase and some of these patients had a simultaneous myopic change. This finding does not support the previous hypothesis that the depth of the anterior chamber plays a major role in the mechanism of myopia [18]. Another commonly discussed feature claimed to account for the myopic shift is thickening of the lens $[16,18]$. In our study, thickening of the lens was noted in $82 \%$ of all NE cases encompassing the patients with a myopic refraction change. The increased thickness of the lens evokes a myopic change by steepening the anterior and posterior curvatures of the lens. In addition, the refractive index of the lens may change due to changes in osmolarity of both the lens and the aqueous humor during acute NE. Simultaneously with the thickening of the lens, the length of the vitreous cavity tended to be shallower in acute phase than in the control phase despite the possible forward movement of the lens in acute NE. In contrast to a previous work [18], no significant change in the axial length of the eyes in the acute phase was noted. These results suggest that thickening of the lens seems to be the key factor in the mechanism contributing to the myopic change in acute NE.

Contradictory results of IOP level in patients with NE have been published $[12,15,16,19,24]$ and 
there are some reports of acute glaucoma attacks associated with NE [12, 15, 16, 24]. The increased IOP has been speculated to be due to edema and haemorrhage in the ciliary body, its anterolateral rotation, relaxation of the zonules and the anterior movement of the lens [12]. There are several reports of decreased IOP during acute NE $[16,19]$, although a case of an acute glaucoma attack was documented in one of these series of patients [16]. In a previous work, IOP declined in $66 \%$ and increased or remained unchanged in $34 \%$ of the patients, whereas the mean differences in IOP between the phases were less than $2 \mathrm{mmHg} 1.8 \mathrm{mmHg}$ in the right and $1.9 \mathrm{mmHg}$ in the left eyes [19]. In agreement with these works, our results indicate an even more significant $(4.0 \mathrm{mmHg}$ and $3.6 \mathrm{mmHg}$ in the right and left eyes, respectively) decrease in IOP between the phases. In contrast to some previous studies $[12,15,16,24]$, there were no cases of acute angle-closure attack in our patients. We thus conclude that decreased IOP is a general characteristic of acute NE. However, we can not rule out the possibility that the observed change may not be specific for NE; potential IOP alterations during other febrile illnesses are not well understood.

It is known that the acute phase of NE causes increased tissue permeability [25]. Leakage of erythrocytes has been described as interstitial hemorrhages in many organs including conjunctiva and retina $[15,16]$ which could explain the finding of subconjunctival bleeding and frequent conjunctival chemosis in our patients. In some previous studies, $724 \%$ of the several patients have been diagnosed with anterior uveitis during the acute $\mathrm{NE}[11,13,15,16,20]$. On the contrary, no cases of uveitis connected to acute NE were recorded in our study. Interestingly, a prior study has reported that uveitis had subsided without the need for a medical therapy [20], suggesting that the increase in tissue permeability in the capillary endothelial cells of the ciliary body may have triggered a condition resembling uveitis rather than actual inflammation of the uvea. We speculate that edema and hemorrhages in the ciliary body may cause decreased aqueous formation and diminished filtration due to damage to the capillary endothelial cells which would subsequently lead 
to the decreased IOP. It is possible that the decreased filtration of the ciliary body and the simultaneous disturbed kidney function may share similar biological mechanisms.

In our study, visual acuity was diminished in $87 \%$ of the patients with acute NE. This cannot be completely explained by myopization, which was documented in $74 \%$ of the cases. Thus, $18 \%$ of the patients had no change in the refraction power but most patients still suffered from reduced blurred vision during the acute phase. In some of these patients, normal vision was not achievable even with best spectacle correction and there were no signs of other features, i.e. retinal edema, haemorrhages or uveitis, which would possibly account for the impaired visual acuity. This interesting feature leads us to conclude that the visual disturbances encountered in acute NE can be caused by multiple mechanisms. Extraocular origins, such as CNS involvement, cannot be ruled out in patients with severe NE as a potential explanation of the ecular visual changes. In order to clarify these mechanisms, for example, the role of CNS involvement during acute NE should be investigated.

\section{COMPETING INTEREST}

None declared.

\section{LICENCE FOR PUBLICATION}

I, Nina Hautala, The Corresponding Author of this article has the right to grant on behalf of all authors and does grant on behalf of all authors, a licence to the BMJ Publishing Group Ltd and its licensees, to permit this Contribution (if accepted) to be published in British Journal of Ophthalmology $(\mathrm{BJO})$ and any other BMJ Group products and to exploit all subsidiary rights, as set out in our licence set out at: (http://bjo.bmj.com/site/about/licence.pdf). 


\section{REFERENCES}

1 Vapalahti O, Mustonen J, Lundkvist A, et al. Hantavirus infections in Europe. Lancet Infect Dis. 2003;3:653-61.

2 Kariwa H, Yoshimatsu K, Arikawa J. Hantavirus infection in East Asia. Comp Immunol Microbiol Infect Dis. 2007;30:341-56.

3 Brummer-Korvenkontio M, Vapalahti O, Henttonen H, et al. Epidemiological study of nephropathia epidemica in Finland 1989-96. Scand J Infect Dis. 1999;31:427-35.

4 Tersago K, Verhagen R, Servais A, et al. Hantavirus disease (nephropathia epidemica) in Belgium: effects of tree seed production and climate. Epidemiol Infect. 2009;137(2):250-6.

5 Forslund T, Saltevo J, Anttinen J, et al. Complications of nephropathia epidemica: three cases. $J$ Intern Med. 1992;232:87-90.

6 Hautala T, Sironen T, Vapalahti O, et al. Hypophyseal hemorrhage and panhypopituitarism during Puumala virus infection: magnetic resonance imaging and detection of viral antigen in the hypophysis. Clin Infect Dis. 2002;35:96-101.

7 Alexeyev OA, Morozov VG. Neurological manifestations of hemorrhagic fever with renal syndrome caused by Puumala virus: review of 811 cases. Clin Infect Dis. 1995;20:255-8.

8 Toivanen AL, Valanne L, Tatlisumak T. Acute disseminated encephalomyelitis following nephropathia epidemica. Acta Neurol Scand. 2002;105:333-6.

9 Techow G. Akkomodationskrampf als Krankenheitssymptom bei schlammfieberähniclicher Erkrankung. Eine erstemalige und neuartige Beobachtung. Klin Monatbl Augenheilk. 1946;112:14952. 
10 Lähdevirta J. Nephropathia epidemica in Finland: A clinical, histological and epidemiological study. Ann of Clin Res. 1971;3(suppl 8):S1-154.

11 Saari KM, Alanko H. Silmämuutokset epideemisessä nefropatiassa. Duodecim. 1975;91:1114-5.

12 Saari KM. Acute glaucoma in haemorrhagic fever with renal syndrome (nephropathia epidemica). Am J Ophthalmol. 1976;81:455-61.

13 Saari KM, Alanko H, Järvi J, et al. Nephropathia epidemica. The Scandinavian form of hemorrhagic fever with renal syndrome. JAMA. 1977;238:874-7.

14 Laatikainen LT, Immonen IJR. Acute posterior multifocal placoid pigment epitheliopathy in connection with acute nephritis. Retina. 1988;8:122-4.

15 Saari KM, Luoto S. Ophthalmological findings in nephropathia epidemica in Lapland. Acta Ophthalmol. 1984;62:235-43.

16 Pärssinen O, Klemetti A, Rossi-Rautiainen E, et al. Ophthalmic manifestations of epidemic nephropathy. Acta Ophthalmol. 1993;71:114-8.

17 Pärssinen O, Kuronen J. Tonic pupillary reaction after epidemic nephropathy and transient myopia. Am J Ophthalmol. 1989;108:201-2.

18 Kontkanen M, Puustjärvi T, Lähdevirta J. Myopic shift and its mechanism in nephropathia epidemica or Puumala virus infection. Br J Ophthalmol. 1994;78:903-6.

19 Kontkanen MI, Puustjärvi TJ, Lähdevirta JK. Intraocular pressure changes in nephropathia epidemica: A prospective study of 37 patients with acute systemic Puumala virus infection. Ophthalmology. 1995;102:1813-7.

20 Kontkanen M, Puustjarvi T, Kauppi P, et al. Ocular characteristics in nephropathia epidemica or 
Puumala virus infection. Acta Ophthalmol. 1996;74:621-5.

21 Ahlm C, Lindén C, Linderholm M, et al. Central nervous system and ophthalmic involvement in nephropathia epidemica (European type of haemorrhagic fever with renal syndrome). $J$ Infect. 1998;36(2):149-55.

22 Hautala T, Mähönen SM, Sironen T, et al. Pituitary injury may complicate acute PUUV hantavirus infection. Ann Med. In press, 2010.

23 Launes J, Hautanen A. Nephropathia epidemica encephalitis. Acta Neurol Scand. 1988;78:234235.

24 Neetens A, Van Den Ende P. Pathogenie de l'elevation de la pression intra-oculaire dans la nephropathie epidemique. Ophthalmologie. 1992;6:414-7.

25 Kanerva M, Mustonen J, Vaheri A. Pathogenesis of Puumala and other hantavirus infections. Rev Med Virol. 1998;8:67-86.

\section{FIGURES AND TABLES}

Table 1. The incidence of eculars symptoms and findings in patients with acute NE.

Table 2. Ocular findings in acute NE compared to control phase. The results are expressed as mean $(\mathrm{SD}) . \mathrm{IOP}=$ intraocular pressure $(\mathrm{mmHg}), \mathrm{ACD}=$ anterior chamber depth $(\mathrm{mm}), \mathrm{VL}=$ vitreous length (mm), AL = axial length (mm). Refraction power is expressed as dioptres (D). RE represents right eye and LE left eye. A p-value $<0.05$ is considered statistically significant, $*$ p $<0.05$ and $* *$ $\mathrm{p}<0.001$. 
Table 1.

\section{Symptoms and findings}

Blurred visual acuity

Conjunctival chemosis

Headache, nausea/vomiting, or dizziness

Light sensitiveness

Foreign-body sensation

Orbital pain

Subconjunctival bleeding

\section{Number of patients $(\%)$}

$40(87 \%)$

$40(87 \%)$

$40(87 \%)$

$22(48 \%)$

$13(28 \%)$

$8(17 \%)$

$1(2 \%)$

Table 2.

IOP (mmHg) Refraction (D) ACD (mm) Lens (mm) VL (mm) AL (mm)

\begin{tabular}{|c|c|c|c|c|c|c|}
\hline \multicolumn{7}{|c|}{ Acute phase } \\
\hline $\mathrm{RE}$ & $10.9(2.9)$ & $-1.0(1.9)$ & $2.9(0.6)$ & $4.6(0.5)$ & $15.5(1.0)$ & $23.1(0.8)$ \\
\hline LE & $11.1(3.3)$ & $-0.7(1.7)$ & $2.8(0.5)$ & $4.5(0.5)$ & $15.6(0.8)$ & $23.0(0.9)$ \\
\hline \multicolumn{7}{|c|}{ Control phase } \\
\hline $\mathrm{RE}$ & $14.9(2.8)$ & $-0.5(1.8)$ & $3.1(0.5)$ & $4.3(0.4)$ & $15.8(1.0)$ & $23.1(1.1)$ \\
\hline $\mathrm{LE}$ & $14.7(2.7)$ & $-0.2(1.5)$ & $3.2(0.4)$ & $4.2(0.4)$ & $15.8(0.9)$ & $23.1(1.0)$ \\
\hline \multicolumn{7}{|c|}{ Difference between the phases } \\
\hline $\mathrm{RE}$ & $4.0 * *$ & $0.5 * *$ & $0.2 *$ & $0.3 * *$ & $0.3 * *$ & 0.1 \\
\hline LE & $3.6 * *$ & $0.5 * *$ & $0.4 * *$ & $0.3 * *$ & $0.2 *$ & 0.1 \\
\hline
\end{tabular}

